\title{
Sourdoughs fermented by autochthonous Lactobacillus strains improve the quality of gluten-free bread
}

\author{
Mehdi Gharekhani $^{1}$ | Yousef Nami ${ }^{2}$ | Mehran Aalami ${ }^{3}$ (D) | Mohammad Amin Hejazi ${ }^{2}$ (ID
}

\author{
${ }^{1}$ Department of Food Science and \\ Technology, Islamic Azad University, Tabriz, \\ Iran \\ ${ }^{2}$ Department of Food Biotechnology, \\ Agricultural Research, Education and \\ Extension Organization (AREEO), \\ Agricultural Biotechnology Research \\ Institute of Iran, Tabriz, Iran \\ ${ }^{3}$ Department of Food Science and \\ Technology, Gorgan University of \\ Agriculture Sciences and Natural Resources, \\ Gorgan, Iran
}

\section{Correspondence}

Mohammad Amin Hejazi, Department of Food Biotechnology, Agricultural Research, Education and Extension Organization (AREEO), Agricultural Biotechnology Research Institute of Iran, Daneshghah Street, Tabriz, Iran.

Email:aminhejazi@abrii.ac.ir

\begin{abstract}
Sourdoughs based on fermentation by lactobacilli have the potential to produce gluten-free maize-based bread with acceptable technological and rheological characteristics, nutritional quality, and more prolonged shelf life. Of the 17 treatments compared (with or without sourdough, and involving single and multiple LAB species), treatments $12 \mathrm{C}$ (Lactobacillus brevis, $L$ sanfranciscensis $+\mathrm{L}$. plantarum), and $8 \mathrm{C}$ (L. brevis + L. paralimentarius) showed the lowest rate of complex modulus, while treatments $11 \mathrm{C}$ (L. sanfranciscensis + L. brevis + L. paralimentarius) and $2 \mathrm{C}$ (L. brevis) led to the greatest reduction in baking loss. The crumb moisture content of all of the formulations decreased with storage. Breads produced with treatment $2 \mathrm{C}$ (L. brevis) had the highest crumb moisture content when freshly baked, while loaves produced with treatment $3 C$ ( $L$. paralimentarius) had the highest crumb moisture content after four days of storage. A sensory evaluation indicated that sourdough-based maize breads were superior to both control and chemically acidified breads. The optimal treatments were to use sourdough seeded with treatment $2 C$ (L. brevis), with treatment 4C (L. plantarum), with treatment 8C (L. brevis + L. paralimentarius), or with treatment 11C (L. sanfranciscensis + L. brevis + L. paralimentarius).
\end{abstract}

\section{KEYWORDS}

gluten-free bread, Lactobacillus, maize, probiotic starters, sourdough

\section{1 | INTRODUCTION}

Bread is the most important food for most people, especially in developing countries. Bread is usually made from wheat flour, but bread from rye, barley, and millet are also common. On average, about $60 \%-65 \%$ of calories and protein and $2-3 \mathrm{~g}$ of mineral salts are provided daily by eating bread. Bread has always been one of the cheapest sources of energy and protein for human. Bread has a prominent role in providing dietary fiber, certain minerals such as calcium, iron, group B vitamins as well as vitamin E. Since the products of the fortune industry have a special place in the food basket of the community, even celiac patients, the use of gluten-free flours such as rice, corn, sorghum, cassava, amaranth, and quinoa are inevitable (Kumar et al., 2019).

Gluten-free (GF) cereal-based foods are required for patients suffering from coeliac disease (Matos \& Rosell, 2015). Producing GF bread acceptable to the consumer is difficult, largely because gluten is the basis of the viscoelastic network required to create bread's characteristic spongy texture. In addition, GF bread tends to suffer from poor color, a short shelf-life, and a generally unsatisfactory organoleptic score (Rinaldi et al., 2017). Although the formulation of the dough used to produce GF bread is critical, the

This is an open access article under the terms of the Creative Commons Attribution License, which permits use, distribution and reproduction in any medium, provided the original work is properly cited.

(c) 2021 The Authors. Food Science \& Nutrition published by Wiley Periodicals LLC. 
fermentation and baking conditions also influence the quality of the product.

Lactic acid bacteria (LAB) can be used to acidify doughs, a process that improves the leavening process and has a positive effect on the quality and shelf-life of wheat bread (Scarnato et al., 2017). Sourdoughs based on a combination of LAB and yeast not only extend the shelf-life of the bread but also improve its nutritional value, flavor, and aroma (Poutanen et al., 2009). The use of LAB does, however, risk-averse effects on dough rheology, since some strains exhibit proteolytic activity. Because of the sensitivity of dough rheology to any ingredients and its related consequence on the GF bread quality, screening, and introduction of new strains of LAB for application in GF bread production is of importance.

One of the most commonly used LAB strains in the production of GF bread is Lactobacillus sanfranciscensis. Both Scarnato et al. (2017) and Vernocchi et al. (2008) have used this LAB, in conjunction with Candida milleri, to improve the aroma and lengthen the shelf-life of a range of GF products.

The present study aimed to improve the quality of maize-based bread through the use of different native LAB isolates belonging to species, namely L. sanfranciscensis, L. plantarum, L. brevis, and L. paralimentarius.

\section{MATERIALS AND METHODS}

\section{1 | Bacteria isolation and identification}

Five lactic acid bacteria ( $L A B$ ), which were isolated from traditional sourdough of East Azerbaijan, were obtained from the bacterial collection of the Agricultural Biotechnology Research Institute of Iran (ABRII). These bacteria were inoculated in de Man Rogosa Sharpe medium (MRS) under sterile conditions and incubated at $37^{\circ} \mathrm{C}$ for 24 h. For molecular identification of bacteria, 16s-rRNA fragments were amplified according to a method of Kiani et al. (2021). The samples were identified and characterized at species levels using BLAST ${ }^{1}$ software (http://blast.ncbi.nlm. nih.gov/Blast.cgi) and by comparing them with the deposited sequences in NCBI and GenBank.

\section{2 | Preparation and characterization of sourdoughs}

Sourdoughs were fermented using one or a combination of the four LAB species L. sanfranciscensis, L. brevis, L. paralimentarius, and L. plantarum. In addition, chemically acidified (CA) and control samples (without starter) were used for fermentation of sourdoughs. In total, 17 treatments were compared, as stated in Table 1 . The doughs were made by mixing maize flour and water to obtain a dough yield (DY) of 200. The various sourdoughs were prepared by seeding maize dough with selected starter cultures. Fermentation was carried out at $30^{\circ} \mathrm{C}$ for $24 \mathrm{hr}$, after which the following parameters were measured, following the methods given by Nami et al. (2019):

\section{Significance Statement}

Of the 17 treatments compared, treatments $12 \mathrm{C}$ and $8 \mathrm{C}$ showed the lowest rate of complex modulus, while treatments $11 \mathrm{C}$ and $2 \mathrm{C}$ led to the greatest reduction in baking loss. The optimal treatments were to use sourdough seeded with treatment $2 \mathrm{C}$, with treatment $4 \mathrm{C}$, with treatment $8 \mathrm{C}$, or with treatment $11 \mathrm{C}$.

$\mathrm{pH}$, total titratable acidity, hydrogen peroxide content, and diacetyl value. A count of the bacteria was also performed.

\section{3 | Dough rheology}

Standard dough rheology tests were conducted, following Moroni et al. (2011). The doughs were held at a constant temperature of $30^{\circ} \mathrm{C}$, using a Peltier Plate System attached to a water circulation unit. Briefly, controlled stress and strain rheometer (Antoon Paar MCR 301) was used to measure rheological parameters. Parallel plate geometry was used for measuring dough samples. Dough samples were allowed to rest for $10 \mathrm{~min}$ before evaluation, and doughs were incubated for one hour at fermentation conditions $\left(30^{\circ} \mathrm{Cand} 75 \%\right.$ humidity) before analysis.

\subsection{GF bread preparation}

The GF bread recipe is comprised of maize flour, water, sugar, salt, egg, baker's yeast, skimmed milk, sodium caseinate, guar gum, edible oil, and sourdough (the amount of each one is stated in Table 2); this formulation produced $\sim 500 \mathrm{~g}$ of dough with a DY of 200 . A $150 \mathrm{~g}$ portion of each dough was baked in a tin $(15 \mathrm{~cm} \times 8.5 \mathrm{~cm} \times 5.7 \mathrm{~cm})$ at $225^{\circ} \mathrm{Cfor} 30 \mathrm{~min}$. The loaves were stored in polyethylene bags after cooling to room temperature (Moore et al., 2008).

\section{5 | Bread and dough physicochemical attributes}

\subsection{1 $\mathrm{pH}$ and Total titratable acidity (TTA)}

The $\mathrm{pH}$ of the dough and bread was obtained by soaking a $10 \mathrm{~g}$ sample in $90 \mathrm{ml}$ distilled water and measuring the $\mathrm{pH}$ with a standard $\mathrm{pH}$ meter. Total titratable acidity values were obtained by recording the volume of $0.1 \mathrm{M} \mathrm{NaOH}$ needed to raise the same sample's $\mathrm{pH}$ to 8.5.

\subsection{2 | Diacetyl and hydrogen peroxide production}

Diacetyl production was calculated by mixing $10 \mathrm{~g}$ sourdough samples in $90 \mathrm{ml}$ distilled water. Afterward, $7.5 \mathrm{ml}$ of hydroxylamine 
TABLE 1 Signs and abbreviations used instead of treatments titles in sourdough, dough, and bread and formulation of GF bread dough preparation

\begin{tabular}{|c|c|c|c|c|c|}
\hline \multicolumn{4}{|c|}{ formulation of GF bread dough preparation } & \multirow{2}{*}{$\begin{array}{l}\text { Signs and abbreviations of used strains } \\
\text { in treatments } \\
\text { LAB Strains }\end{array}$} & \multirow[b]{2}{*}{ Treatments } \\
\hline $\begin{array}{l}\text { Acid-Chemical } \\
\text { Dough }\end{array}$ & Sourdough Dough & Control Dough & Raw materials & & \\
\hline 100 & 92.5 & 100 & Flour & L. sanfranciscensis & $1 C$ \\
\hline 2 & 2 & 2 & Salt & L. brevis & $2 \mathrm{C}$ \\
\hline 3 & 3 & 3 & Yeast & L. plantarum & $4 \mathrm{C}$ \\
\hline 12 & 12 & 12 & Egg & L. sanfranciscensis + L. brevis & $5 \mathrm{C}$ \\
\hline 1.5 & 1.5 & 1.5 & Sodium Caseinate & L. sanfranciscensis + L. paralimentarius & $6 C$ \\
\hline 5 & 5 & 5 & Skim milk & L. sanfranciscensis + L. plantarum & 7C \\
\hline 3 & 3 & 3 & Guar Gum & L. brevis + L. paralimentarius & $8 \mathrm{C}$ \\
\hline \multirow[t]{4}{*}{110} & 102.5 & 110 & Water & $\begin{array}{l}\text { L. sanfranciscensis }+ \text { L. brevis }+ \text { L. } \\
\text { plantarum }\end{array}$ & $12 \mathrm{C}$ \\
\hline & & & & $\begin{array}{l}\text { L. brevis }+ \text { L. paralimentarius }+L \text {. } \\
\text { plantarum }\end{array}$ & $13 C$ \\
\hline & & & & $\begin{array}{l}\text { L. sanfranciscensis }+L \text {. } \\
\quad \text { paralimentarius }+ \text { L. plantarum }\end{array}$ & $14 \mathrm{C}$ \\
\hline & & & & $\begin{array}{l}\text { L. sanfranciscensis + L. brevis }+ \text { L. } \\
\quad \text { paralimentarius + L. plantarum }\end{array}$ & $15 \mathrm{C}$ \\
\hline
\end{tabular}

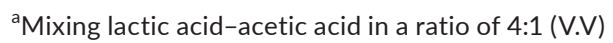

solution (1 M) was added to $25 \mathrm{ml}$ of the homogenized mixture, and samples were titrated by $0.1 \mathrm{~N} \mathrm{HCl}$ to final $\mathrm{pH}$ 3.4. The equivalence factor of $\mathrm{HCl}$ to diacetyl is $21.52 \mathrm{mg}$. The concentration of produced diacetyl was measured according to a method of Edema and Sanni (2008).

Hydrogen peroxide production was evaluated by adding $25 \mathrm{ml}$ of $10 \% \mathrm{H}_{2} \mathrm{SO}_{4}$ to $25 \mathrm{ml}$ of homogenized mixture (from the same batch used for diacetyl). It was then titrated with $0.1 \mathrm{~N}$ potassium permanganate $\left(\mathrm{KMnO}_{4}\right)$ so that the pale pink color persisted for $15 \mathrm{~s}$ before de-colorization. Each $\mathrm{mL}$ of $0.1 \mathrm{~N} \mathrm{KmnO}_{4}$ is equivalent to $1.701 \mathrm{mg}$ of $\mathrm{H}_{2} \mathrm{O}_{2}$. The concentration of produced $\mathrm{H}_{2} \mathrm{O}_{2}$ was calculated as follows Edema and Sann (2008):

$$
\mathrm{H}_{2} \mathrm{O}_{2} \text { concentration }=\frac{\mathrm{KMnO} 4(\mathrm{~mL}) \times \mathrm{KMnO} 4(\mathrm{~N}) \times \mathrm{E} \times 100}{\mathrm{H} 2 \mathrm{SO} 4(\mathrm{~mL}) \times \text { volume of sample }}
$$

\subsection{3 | LAB cell counts}

A $10 \mathrm{~g}$ sample of sourdough was homogenized in $90 \mathrm{ml} 0.15 \mathrm{M} \mathrm{NaCl}$ and serial dilutions were prepared in phosphate-buffered saline (PBS). The dilutions were plated in triplicate on MRS agar and incubated for $48 \mathrm{~h}$ at $30^{\circ} \mathrm{C}$.

\subsubsection{Crumb and crust color}

Bread crumb and crust color evaluations were performed following Marti et al., 2017). Values for $L^{*}, a^{*}$, and $b^{*}$ (as measures of lightness, redness-greenness, and yellowness-blueness, respectively) were measured for each sample. Each measurement was replicated three times.

\subsection{5 | Specific bulk volume and height}

The specific volume of three replicate loaves per formulation was measured using the rapeseed displacement method (AACC10-05), performed one hour after baking. The loaves were weighed and their specific volume was determined from the volume/mass ratio $(\mathrm{mL} / \mathrm{g})$. A pair of digital calipers was used to estimate loaf height.

\subsection{6 | Moisture content}

The moisture content of the bread was measured following $\mathrm{AACC}^{2}$ standard method 44-16 (AACC, 2000). The moisture content of the 
TABLE 2 Changes in $\mathrm{pH}$ and TTA in the dough and gluten-free bread

\begin{tabular}{|c|c|c|c|c|}
\hline \multirow[b]{2}{*}{ Treatment } & \multicolumn{2}{|l|}{ Fermented dough } & \multicolumn{2}{|l|}{ Bread } \\
\hline & $\mathrm{pH}$ & TTA (ml) & $\mathrm{pH}$ & TTA (ml) \\
\hline $1 C$ & $5.360 \pm 0.010^{f}$ & $3.85 \pm 0.12^{\mathrm{fgh}}$ & $6.193 \pm 0.006^{c d}$ & $2.400 \pm 0.070^{\mathrm{hr}}$ \\
\hline $2 C$ & $5.463 \pm 0.006^{c}$ & $4.11 \pm 0.16^{\text {defg }}$ & $6.180 \pm 0.017^{\mathrm{cde}}$ & $2.640 \pm 0.135^{\mathrm{g}}$ \\
\hline $3 C$ & $5.390 \pm 0.010 \mathrm{def}$ & $4.20 \pm 0.14$ def & $6.190 \pm 0.026^{c d}$ & $2.756 \pm 0.125^{\mathrm{fg}}$ \\
\hline $4 C$ & $5.413 \pm 0.011^{\mathrm{de}}$ & $3.93 \pm 0.18^{\text {efgh }}$ & $6.166 \pm 0.029$ defg & $2.900 \pm 0.120^{\operatorname{defg}}$ \\
\hline $5 C$ & $5.364 \pm 0.025^{f}$ & $3.72 \pm 0.26^{\mathrm{hr}}$ & $6.179 \pm 0.011^{\mathrm{cde}}$ & $2.933 \pm 0.045^{\text {cdef }}$ \\
\hline $6 C$ & $5.377 \pm 0.020^{\text {ef }}$ & $4.33 \pm 0.18^{\mathrm{cd}}$ & $6.157 \pm 0.031^{\operatorname{defg}}$ & $3.190 \pm 0.135^{b c}$ \\
\hline 7C & $5.390 \pm 0.020$ def & $4.58 \pm 0.49^{b c}$ & $6.173 \pm 0.021^{\text {cdef }}$ & $3.056 \pm 0.190^{\text {cde }}$ \\
\hline $8 C$ & $5.426 \pm 0.025^{c d}$ & $4.21 \pm 0.04$ def & $6.190 \pm 0.007^{c d}$ & $2.953 \pm 0.096^{\text {cdef }}$ \\
\hline $9 \mathrm{C}$ & $5.366 \pm 0.025^{f}$ & $3.81 \pm 0.06^{g h}$ & $6.210 \pm 0.010^{b c}$ & $3.003 \pm 0.035^{\text {cdef }}$ \\
\hline $10 \mathrm{C}$ & $5.346 \pm 0.005^{f}$ & $3.91 \pm 0.11$ efgh & $6.107 \pm 0.012^{h i}$ & $3.357 \pm 0.060^{\mathrm{ab}}$ \\
\hline $11 C$ & $5.533 \pm 0.040^{b}$ & $4.15 \pm 0.19$ defg & $6.206 \pm 0.015^{b c}$ & $2.800 \pm 0.100^{\mathrm{efg}}$ \\
\hline $12 \mathrm{C}$ & $5.513 \pm 0.045^{b}$ & $4.73 \pm 0.11^{\mathrm{ab}}$ & $6.143 \pm 0.010^{\mathrm{efg}}$ & $3.007 \pm 0.160^{\text {cdef }}$ \\
\hline $13 C$ & $5.533 \pm 0.015^{b}$ & $4.23 \pm 0.17^{\mathrm{de}}$ & $6.134 \pm 0.011^{g h}$ & $3.463 \pm 0.190^{a}$ \\
\hline $14 C$ & $5.536 \pm 0.021^{b}$ & $4.05 \pm 0.06^{\text {defgh }}$ & $6.231 \pm 0.022^{b}$ & $2.847 \pm 0.117^{\text {efg }}$ \\
\hline $15 \mathrm{C}$ & $5.514 \pm 0.027^{b}$ & $4.96 \pm 0.14^{a}$ & $6.087 \pm 0.035^{i}$ & $3.163 \pm 0.091^{\mathrm{bcd}}$ \\
\hline $16 C$ & $5.507 \pm 0.012^{b}$ & $3.95 \pm 0.15^{\text {efgh }}$ & $6.141 \pm 0.024^{\mathrm{fgh}}$ & $2.950 \pm 0.190^{\text {cdef }}$ \\
\hline $17 C$ & $5.837 \pm 0.037^{a}$ & $3.22 \pm 0.17^{i}$ & $6.456 \pm 0.022^{a}$ & $1.823 \pm 0.315^{i}$ \\
\hline
\end{tabular}

Note: Same letter in each column represent no significant difference in the level of $5 \%(p<.05)$. crust and central crumb of fresh loaves was recorded, and similar measurements were taken after storage of the loaves for two and four days.

\subsection{7 | Baking loss}

The baking loss was obtained from weight measurements taken before and after baking, according to the following formula:

Baking loss $(\%)=\frac{\text { weight of dough of each loaf }- \text { weight of bread after baking }}{\text { weight of dough of each loaf }} \times 100$

\subsection{8 | Bread porosity}

The Wolter et al. (2014) method was used to obtain estimates of the percentage crumb porosity.

\subsection{9 | Crumb and crust hardness}

A textural profile analysis was performed on the crumb and a penetration test quantifies crust hardness. Both tests utilized methods described by Crowley et al. (2002).

\section{6 | Organoleptic attributes of bread}

The organoleptic attributes of the breads were determined following a standard protocol (ISO 8,587, 1988) which employed a panel of twelve trained judges. An overall organoleptic score was based on the individual assessments of crust and crumb color, porosity, elasticity, acidic smell, texture softness, chewiness, and taste. The texture characteristics, chewiness, and taste were first evaluated $2 \mathrm{~h}$ after baking, then again after two and four days of storage.

\subsection{Shelf-life evaluation}

The breads were enclosed in polyethylene bags after cooling and cutting with a sterile knife. The number of days of storage at room temperature required for the appearance of mold was considered as the bread's shelf life (Moore et al., 2008).

\section{8 | Statistical analyses}

The data were statistically analyzed using routines implemented in SAS v9.0 software (SAS Institute). For all tests, a completely randomized design with one-way ANOVA was used. Significant statistical difference was evaluated between the means at the $95 \%$ probability level using Duncan's multiple range tests. The data are presented in the form of mean \pm standard error $(n=3)$.

\section{3 | RESULTS AND DISCUSSION}

\section{1 | Bacteria isolation and identification}

The fragments $(1,500 \mathrm{bp})$ of the 16S-rRNA gene were sequenced for molecular identification of the isolates. Based on sequencing 


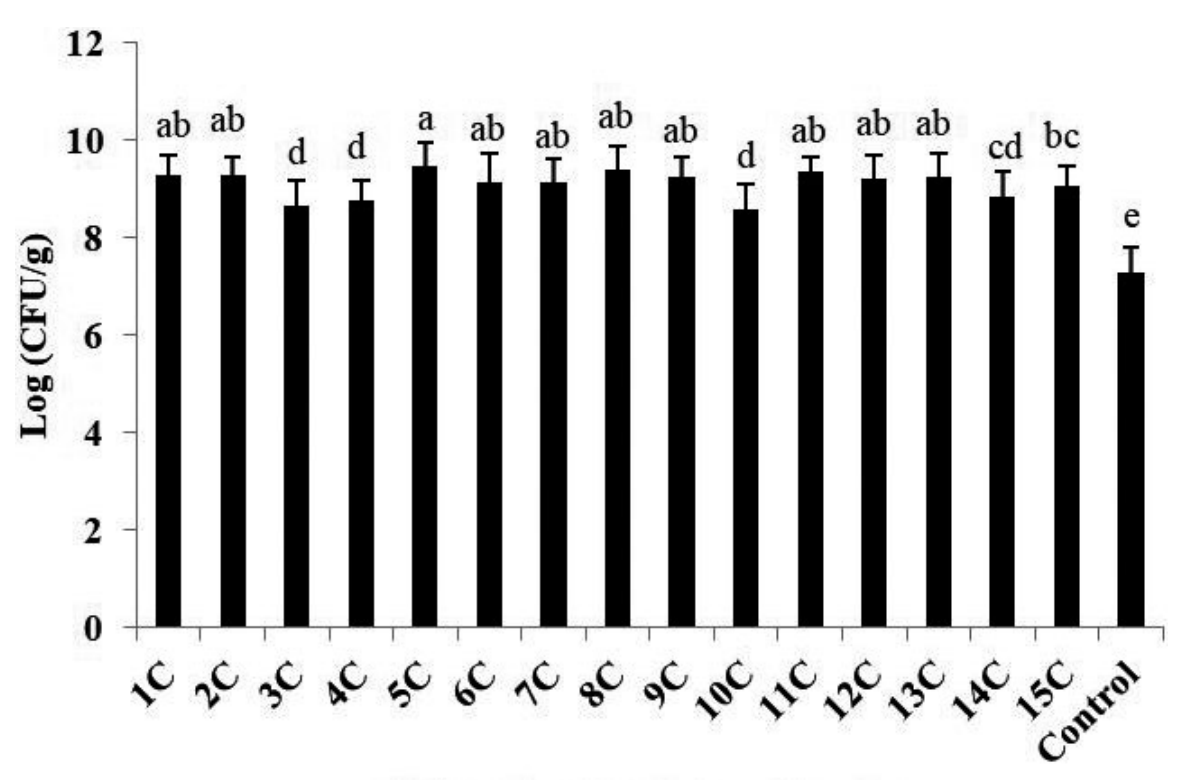

FIGURE 1 The impact of different starters on the LAB population of maize sourdough

\section{Different composition of starters}

results, five strains belonged to four species, namely Lactobacillus brevis, Lactobacillus sanfranciscensis, Lactobacillus plantarum, and Lactobacillus paralimentarius (Table 1).

\section{2 | Sourdough preparation and characterization}

Both the single LAB strain and combined strain starter cultures significantly increased the acidity (decreased the $\mathrm{pH}$ ) and total titratable acidity of the sourdoughs. The highest total titratable acidity $(9.05 \pm 0.095 \mathrm{ml})$ was associated with the treatment 9C (L. brevis $+\mathrm{L}$. plantarum) and the lowest $(6.24 \pm 0.360 \mathrm{ml})$ with the control doughs to which no starter had been added. The sourdough which accumulated the most diacetyl $(34.45 \pm 1.510 \mathrm{mg} / \mathrm{ml})$ was produced using treatment $6 \mathrm{C}$ (L. paralimentarius + L. sanfranciscensis), while the one accumulating the most hydrogen peroxide $(3.90 \pm 0.126 \mathrm{mmol} / \mathrm{L})$ was produced using treatment $1 \mathrm{C}$ (L. sanfranciscensis). The variation in the size of the LAB populations at the end of the fermentation period is illustrated in Figure 1. The largest population developed from treatment 5C (L. sanfranciscensis + L. brevis). An analysis of variance confirmed that the nature of the starter culture had a significant effect on the growth of the LAB in the sourdough.

The effect of the various starter cultures on dough and bread $\mathrm{pH}$ and total titratable acidity (Table 3 ) implied that the incorporation of sourdough significantly reduced $\mathrm{pH}$ and increased acidity in both bread and sourdough. Treatment 15C (sourdough seeded with L. plantarum + L. brevis + L. paralimentarius + L. sanfranciscensis) was associated with the lowest bread $\mathrm{pH}$, while treatment $13 \mathrm{C}$ produced the highest total titratable acidity.

Effects of starters on the amount of diacetyl and hydrogen peroxide production were statistically significant $(p<.05)$ in sourdoughs (not shown). Starter-containing sourdoughs showed a higher amount of diacetyl and hydrogen peroxide than starter-free sourdoughs. Among the sourdoughs, starter $6 \mathrm{C}$ showed a significant increase in the amount of diacetyl comparing with other starters, while starter $1 \mathrm{C}$ showed the highest amount of hydrogen peroxide.

\section{3 | Dough rheology}

A frequency sweep test was performed to evaluate the effect of the nature of the starter culture on the rheological properties of control (no additives, $\mathrm{CO}$ ) and chemically acidified (CA) breads. As shown in Figure 2, the $\mathrm{G}^{*}$ parameter increased with $\omega$ throughout and was highest in $\mathrm{CO}$ dough. Both the addition of acid to the dough and the inclusion of sourdough reduced dough stiffness. The comparison between CA dough and those produced by seeding with sourdough starter cultures revealed that the latter induced a greater fall in $\mathrm{G}^{*}$. Treatments $2 \mathrm{C}, 7 \mathrm{C}, 8 \mathrm{C}, 13 \mathrm{C}$, and $15 \mathrm{C}$ all produced doughs with a lower $\mathrm{G}^{*}$ than those formed by seeding with any of the other starter cultures. For all doughs, the $\delta$ value decreased with increasing $\omega$. CO dough was the most elastic, followed by CA dough; doughs produced from treatments $8 \mathrm{C}$ and $2 \mathrm{C}$ were associated with the highest $\delta$ value.

Edema and Sanni (2008) have reported that employing L. brevis in a starter culture for maize sourdough was highly effective in terms of boosting its diacetyl content, while the best results with respect to hydrogen peroxide content were obtained using a combination of L. plantarum and L. brevis. These conclusions were borne out in the present experiments. According to Clarke et al. (2002), in wheat breads, the addition of sourdough (L. plantarum and L. brevis) had the effect of increasing $\delta$ and reducing dough elasticity. In bread formulated with GF flour, the $\mathrm{G}^{*}$ value is boosted by the inclusion of sourdough, thereby stiffening the dough.

\subsection{Bread crumb and crust color}

Color, texture, and aroma are all important quality traits in bakery products (Esteller et al., 2006). Color is usually quantified by a 
TABLE 3 Effect of different starters on colored indices of maize bread crumb and crust

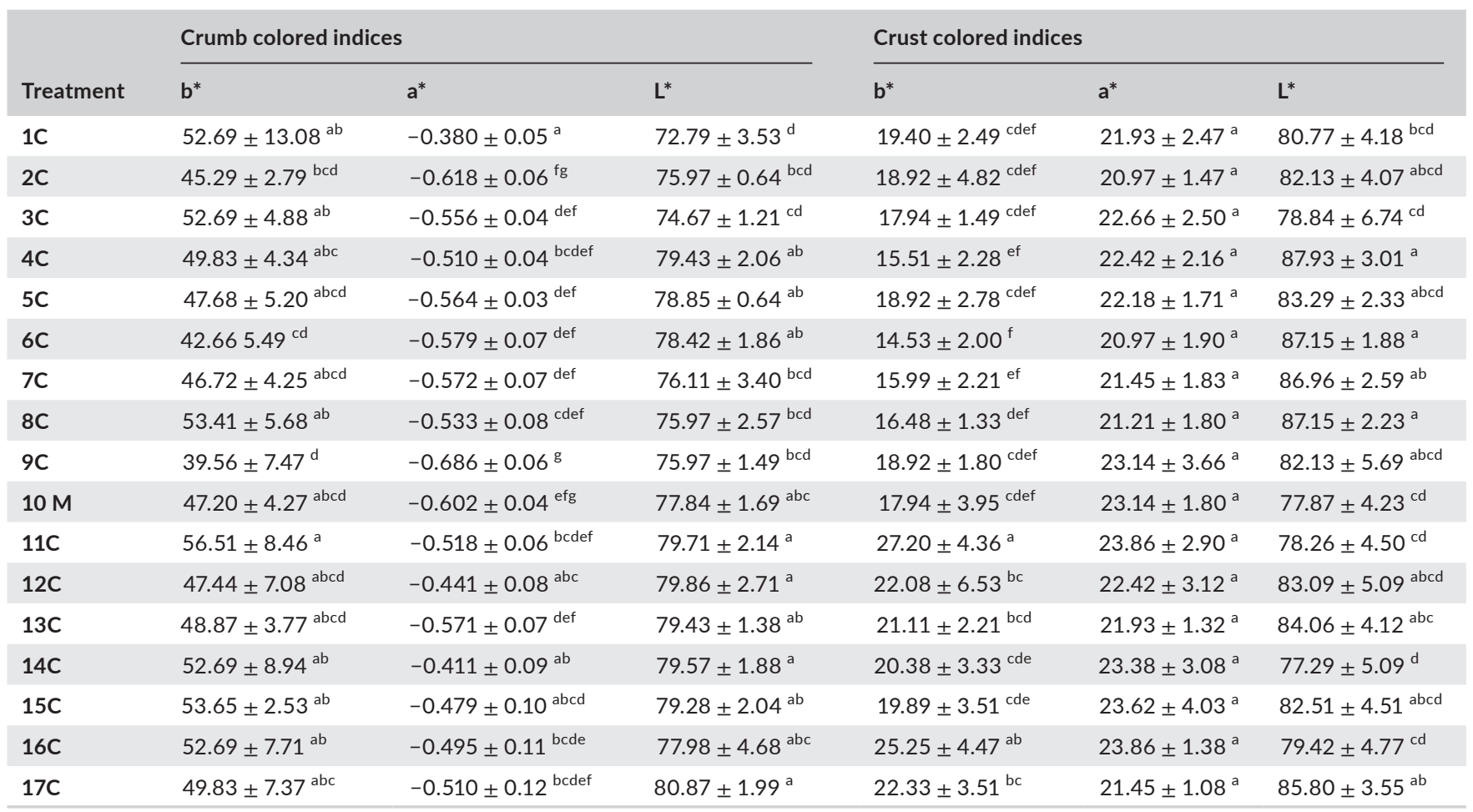

Note: Same letter in each column represent no significant difference in the level of $5 \%(p<.05)$.

combination of the parameters $L^{*}, a^{*}$, and $b^{*}$. The effect of the various sourdoughs on bread crumb and crust color is shown in Table 4. The addition of sourdough decreased light crumb compared with that present in CO bread. Treatment $1 \mathrm{C}$ (L. sanfranciscensis) induced lower light and the most intense crumb redness. There was no significant difference between sourdough starter cultures and $\mathrm{CO}$ with respect to either $L^{*}$ or $a^{*}$, but the use of most of the various sourdoughs did decrease $b^{*}$ (the yellowness crust value)-the exceptions were treatments 11C, 12C (L. sanfranciscensis + L. brevis + L. plantarum), and 13C.

Aplevicz et al. (2014) showed that the crust color of sourdoughbased breads (L. plantarum) was lighter than starter-based breads but was less bright than that of CO bread.

\subsection{Crumb and crust hardness}

Crust and crumb hardness was significantly affected by both the identity of the starter culture type and the storage time. Breads produced from doughs subjected to treatment $2 \mathrm{C}$ produced the lowest crumb hardness $(800.05 \mathrm{~g})$ measured on fresh loaves, but in general, the sourdough-based breads produced a harder crumb structure than did either the $\mathrm{CO}$ or the CA breads. The highest crumb hardness values for fresh loaves were associated with breads prepared from doughs subjected to treatment $13 \mathrm{C}$. After storage for two days, breads produced from doughs subjected to treatments $2 \mathrm{C}, 8 \mathrm{C}$, and $7 \mathrm{C}$ had a softer crumb than the others, while after four days of storage, breads produced from doughs subjected to treatments $8 \mathrm{C}(1,273.71 \mathrm{~g})$ and $7 \mathrm{C}(1,227.44 \mathrm{~g})$ had a softer crumb than those prepared from sourdoughs seeded with a single LAB starter culture and CO bread. Crust hardness declined during storage (data not shown). Breads produced from doughs subjected to treatment $8 \mathrm{C}$ had a hardness value of $474.46 \mathrm{~g}$ when fresh and $401.44 \mathrm{~g}$ after two days: this treatment produced the softest crust. The hardest crusts were associated with CA and CO breads. Treatment $15 \mathrm{C}$ produced loaves with the softest crust at the end of the storage period. The hardest crusts were associated with breads produced from doughs subjected to treatments 11C, 5C, 9C, 14C, along with CO and CA breads.

With respect to the breakdown of the texture of bread during storage, the reductions observed in the maize-based breads are consistent with the literature (Clarke et al., 2002). According to Moore et al. (2008), the texture of GF breads is influenced by storage time and its interaction with the formulation of dough: crumb hardness increases over time but more so in CA than in either sourdoughbased or $\mathrm{CO}$ bread. The inclusion of sourdough has been documented to delay the staling of GF breads (Corsetti et al., 2000) have suggested that $L A B$-mediated acidification encourages starch hydrolysis, proteolysis, and various other physicochemical changes during the course of storage. When Moroni et al. (2011) evaluated buckwheat-based sourdoughs seeded with different starter cultures for the production of wheat breads; it was found that their inclusion had a marked effect on dough rheology: it reinforced the action of the gluten network, and so reduced dough elasticity. This produced both an increase in loaf-specific volume and a softening of the crumb structure. The rate at which the crumb hardens is influenced by both the starter culture type and the proportion of the dough made up by sourdough (Novotni et al., 2013): at low proportions of the latter, 

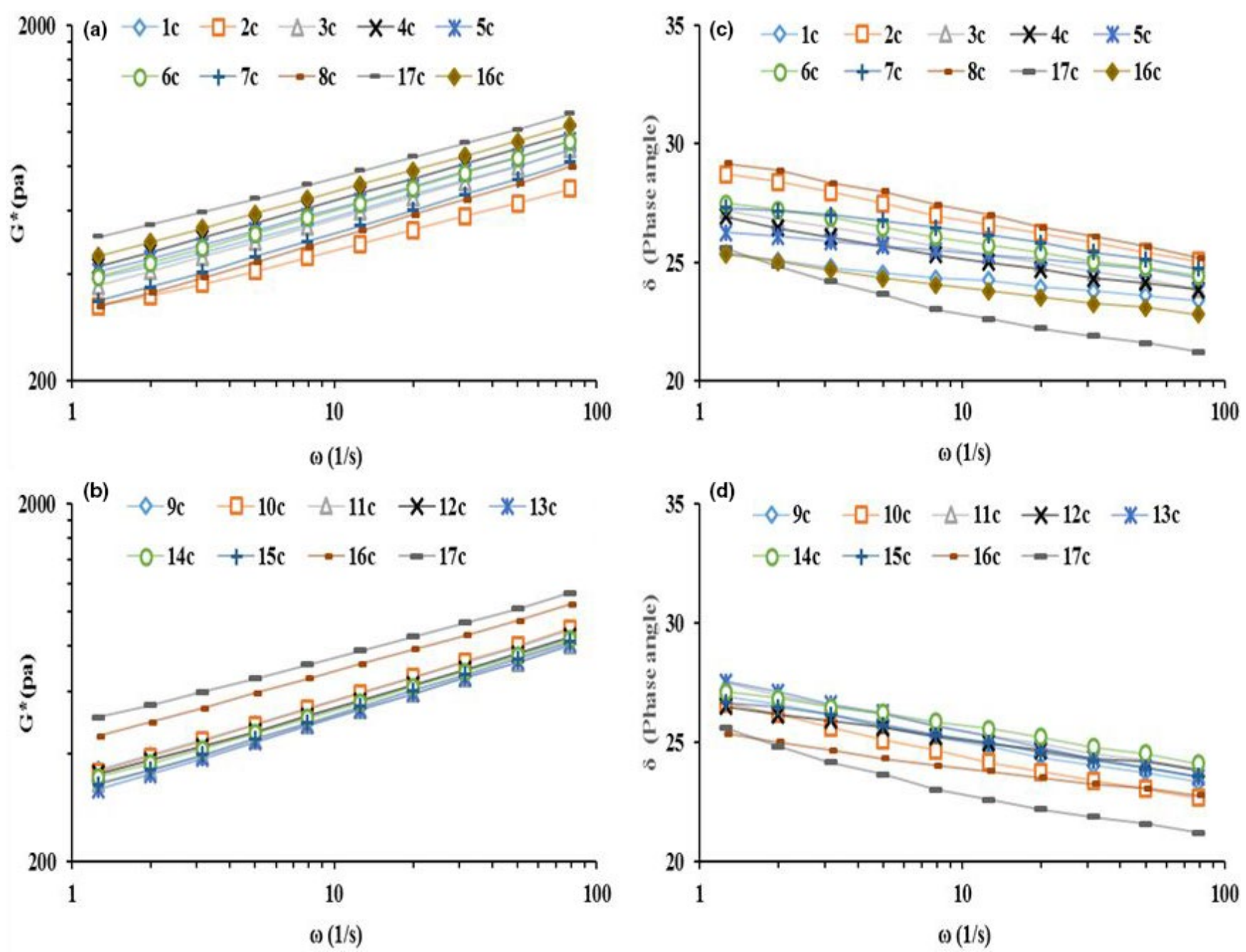

FIGURE 2 Comparison of the complex modulus (G*, Panels a, b) and phase angle ( $\delta$, Panels c, d) of maize doughs with increasing frequency $(\omega)$

there was no effect of adding the sourdough but higher proportions (22.5\% and $30 \%$ ) were effective in increasing crumb firmness.

\subsection{Specific volume and height of breads}

The starter cultures had a significant effect on both the height and specific volume of the bread. The highest specific volume was produced by breads subjected to treatment $3 \mathrm{C}$ (sourdough seeded with L. paralimentarius); the lowest specific volume was associated with CA bread. According to Mert et al. (2014), GF doughs can be softened by the addition of sourdough, as this encourages the expansion of gas bubbles during fermentation; it also raises the specific volume of the loaf since it improves the dough's capacity to retain carbon dioxide.

\section{7 | Moisture content of breads}

Analyses of variance (not shown) suggested that the nature of the starter culture, the post-baking storage time, and their interaction all had a significant effect on the moisture content of the crust and crumb. The moisture content of the crumb was consistently reduced as the storage time was extended, while that of the crust increased. Immediately after baking, bread made from dough subjected to either of the treatments $12 \mathrm{C}$ and $11 \mathrm{C}$ retained the most moisture; after four days of storage, breads made from dough subjected to either of the treatments 3C, 7C, 9C, and 10C (L. paralimentarius + L. plantarum) retained the most moisture. The lowest moisture content after storage was recorded by CA loaves. In conjunction with the maize crust moisture, bread made from dough subjected to either of the treatments $7 \mathrm{C}$ and $8 \mathrm{C}$ retained the least moisture immediately both after baking and after four days of storage.

The moisture content of sourdough-based wheat breads falls during storage (Aplevicz et al., 2014), although breads based on sourdoughs formulated with L. plantarum are able to retain higher moisture content and thus are more palatable than $\mathrm{CO}$ breads. As a result, our findings are consistent with these researchers. However, (Ryan et al., 2011) were not able to find any difference in the crumb moisture content of CO, CA, and sourdough-based bread fermented with L. amylovorus. There was, similarly, in the materials investigated by (Barber 
TABLE 4 Effect of different starters on traits of gluten-free maize bread

\begin{tabular}{|c|c|c|c|c|}
\hline Treatment & Height $(\mathrm{cm})$ & Porosity (\%) & $\begin{array}{l}\text { Specific volume } \\
(\mathrm{ml} / \mathrm{g})\end{array}$ & Baking loss (\%) \\
\hline $1 C$ & $4.93 \pm 0.21^{\text {cdefg }}$ & $29.20 \pm 1.77^{a b}$ & $2.770 \pm 0.078 \mathrm{ab}$ & $16.39 \pm 0.30^{e}$ \\
\hline $2 \mathrm{C}$ & $5.27 \pm 0.15^{\mathrm{ab}}$ & $25.90 \pm 0.10^{\mathrm{bcd}}$ & $2.743 \pm 0.188^{a b c}$ & $15.52 \pm 0.44^{f}$ \\
\hline $3 C$ & $5.17 \pm 0.15^{\mathrm{bcd}}$ & $26.53 \pm 1.01^{\mathrm{bcd}}$ & $2.812 \pm 0.041^{a}$ & $16.79 \pm 0.65^{\mathrm{e}}$ \\
\hline $4 C$ & $5.47 \pm 0.25^{a}$ & $24.53 \pm 1.27^{c d}$ & $2.73 \pm 0.032^{\mathrm{abcd}}$ & $18.58 \pm 0.55^{\mathrm{bcd}}$ \\
\hline $5 C$ & $5.20 \pm 0.26^{b c}$ & $26.03 \pm 2.61 \mathrm{bcd}$ & $2.579 \pm 0.079$ bcdef & $18.33 \pm 0.43^{c d}$ \\
\hline $6 C$ & $4.93 \pm 0.12^{\text {cdefg }}$ & $26.20 \pm 2.43^{b c d}$ & $2.739 \pm 0.103^{a b c}$ & $18.06 \pm 0.23^{d}$ \\
\hline 7C & $4.87 \pm 0.15^{\text {efg }}$ & $27.13 \pm 3.04^{b c}$ & $2.529 \pm 0.036^{\text {cdef }}$ & $18.15 \pm 0.30^{d}$ \\
\hline $8 C$ & $5.19 \pm 0.15^{b c}$ & $26.66 \pm 1.85^{b c d}$ & $2.748 \pm 0.077^{a b c}$ & $19.16 \pm 0.10^{b}$ \\
\hline $9 \mathrm{C}$ & $5.20 \pm 0.13^{b c}$ & $31.60 \pm 1.97 \mathrm{a}$ & $2.517 \pm 0.137^{\text {def }}$ & $17.99 \pm 0.23^{d}$ \\
\hline $10 \mathrm{C}$ & $5.10 \pm 0.10^{\text {bcdef }}$ & $27.60 \pm 1.08^{b c}$ & $2.699 \pm 0.079 \mathrm{abcd}$ & $20.54 \pm 0.23^{a}$ \\
\hline $11 C$ & $5.13 \pm 0.08^{\mathrm{bcde}}$ & $23.17 \pm 1.59^{d}$ & $2.744 \pm 0.033^{a b c}$ & $15.16 \pm 0.29^{f}$ \\
\hline $12 \mathrm{C}$ & $4.97 \pm 0.15^{\text {cdefg }}$ & $23.16 \pm 2.18^{d}$ & $2.687 \pm 0.168^{\mathrm{abcd}}$ & $18.64 \pm 0.56^{\mathrm{bcd}}$ \\
\hline $13 C$ & $4.90 \pm 0.10^{\operatorname{defg}}$ & $27.50 \pm 1.91 \mathrm{bc}$ & $2.645 \pm 0.029$ abcde & $20.61 \pm 0.12^{\mathrm{a}}$ \\
\hline $14 C$ & $5.13 \pm 0.06^{\mathrm{fg}}$ & $22.90 \pm 4.10^{d}$ & $2.562 \pm 0.172^{\text {bcdef }}$ & $20.38 \pm 0.30^{a}$ \\
\hline $15 \mathrm{C}$ & $4.75 \pm 0.05^{g}$ & $26.83 \pm 1.02^{\mathrm{bcd}}$ & $2.429 \pm 0.139^{f}$ & $18.03 \pm 0.60^{d}$ \\
\hline $16 C$ & $4.75 \pm 0.05^{g}$ & $24.63 \pm 0.78^{c d}$ & $2.522 \pm 0.030$ def & $18.44 \pm 0.35^{c d}$ \\
\hline $17 \mathrm{C}$ & $4.93 \pm 0.10^{\text {cdefg }}$ & $25.67 \pm 1.85^{\mathrm{bcd}}$ & $2.472 \pm 0.197^{\text {ef }}$ & $18.91 \pm 0.43^{b c}$ \\
\hline
\end{tabular}

Note: Same letter in each column represent no significant difference in the level of $5 \%(p<.05)$. et al., 1992), no LAB-dependent impact on moisture content following either baking or storage time. The high moisture content of GF breads reflects the need to include much more water in the dough than is necessary in wheat bread formulations. For example, the oat-based breads described by (Hüttner et al., 2010) had a moisture content of $58 \%$ 61\%. According to Tamani et al. (2013), a benefit of including sourdough based on L. delbrueckii and L. helveticus is that the crumb moisture content falls less rapidly over time. When bread's moisture content is reduced, cross-linking between starch and protein accelerates in intensity, leading to increasing stiffness (Symons \& Brennan, 2004). A high content of exopolysaccharides in sourdough may be responsible for the improvement in water retention and hence a softer crumb structure. However, it may be that the qualitative nature of the exopolysaccharides present is as important as their quantity.

\section{8 | Baking loss}

The choice of starter culture had a significant effect on baking loss (Table 4). Doughs subjected to treatment $11 \mathrm{C}$ showed the lowest percentage of weight loss after baking, while the highest baking losses were observed following treatments $10 \mathrm{C}, 13 \mathrm{C}$, and $14 \mathrm{C}$ (L. sanfranciscensis + L. paralimentarius + L. plantarum). According to Wolter et al. (2014), for all gluten-free breads (except teff bread), the addition of sourdough fermented with Lactobacillus plantarum FST 1.7 significantly reduced the baking loss compared with the control bread. But in wheat sourdough bread, the baking loss increased significantly. There were no significant differences in baking loss between oat sourdough bread, control bread, and chemically acidified bread (Hüttner et al., 2010).

\section{9 | Bread porosity}

The nature of the sourdough significantly influenced bread porosity (Table 4), with treatments $9 \mathrm{C}$ and $14 \mathrm{C}$ showing, respectively, the highest and the lowest porosity.

The porosity of quinoa-based CO bread was improved when the dough was fermented L. amylovorus (Axel et al., 2015), as was also the case when L. plantarum-based sourdough was used to produce bread from buckwheat, quinoa, oats, sorghum, and teff (Wolter et al., 2014). The results of this study are corresponded with the results of Sanz-Penella et al. (2012) in terms of porosity.

\subsection{0 | Organoleptic analysis}

According to the final scores given to the various breads, there was a significant treatment effect, with the sourdough-based breads ranking above both $\mathrm{CO}$ and $\mathrm{CA}$ bread. The highest scores were associated with doughs subjected to treatments $8 \mathrm{C}, 12 \mathrm{C}$, and $15 \mathrm{C}$. Each of the texture softness, chewiness, and taste were significantly affected by starter culture type and all declined during storage (data not shown). With respect to texture softness, the starter culture type effect was significant in both fresh and stored loaves, with the sourdough-based breads performing better than either the $\mathrm{CO}$ or the CA bread. The best treatments with respect to this trait were $7 \mathrm{C}, 8 \mathrm{C}$, and $9 \mathrm{C}$. With respect to both chewiness and taste, there was a significant effect of starter culture type for stored but not for fresh loaves. At day zero, treatments $12 \mathrm{C}$ and $15 \mathrm{C}$ showed the highest score of chewiness, but treatment $16 \mathrm{C}$ (CA bread) had the lowest score of chewiness. After four days of storage, doughs subjected to treatments $2 \mathrm{C}, 5 \mathrm{C}, 7 \mathrm{C}, 8 \mathrm{C}$, 
and $9 \mathrm{C}$ scored most highly for chewiness, while CA bread scored poorly. In terms of taste, the CA bread performed worst for both fresh and stored loaves. For the fresh loaves, there was no significant difference between the sourdough-based breads and CO bread, but after four days of storage, breads produced from doughs subjected to treatments $1 \mathrm{C}, 2 \mathrm{C}, 3 \mathrm{C}, 7 \mathrm{C}, 8 \mathrm{C}$, and $13 \mathrm{C}$ scored most favorably. A comparison between the treatments in terms of taste and the amount of diacetyl present suggested that the higher the diacetyl content, the better the taste score (data not shown).

The inclusion of sourdough has a noticeable impact on flavor, in particular, that based on L. plantarum and L. brevis (Katina et al., 2006). A similar outcome was recorded here for the maize breads. More flavor volatile compounds are formed during the lactic acid fermentation of wholemeal wheat flour-based sourdough than that of white wheat flour-based sourdough (Czerny \& Schieberle, 2002). The higher proteolytic activity characteristic of wholemeal flour (Loponen et al., 2004) promotes the accumulation of amino acids such as leucine and proline, which are the flavor precursors generated by standard yeast fermentation and by the Maillard reaction during baking. The generation of some desirable flavor characteristics (overall taste intensity, roasting, and aftertaste) is accompanied by the less desirable flavors such as pungency and staleness, induced by the formation of acetic acid. Acidification is also known to be key for the induction of proteolysis and the enhancement of roasted flavors during dough fermentation (Thiele et al., 2002). Edema and Sanni (2008), in an evaluation of the effect of L. plantarum, L. brevis, and Leuconostoc mesenteroides on the sensory characteristics of maize-based bread, found that loaves made using a sourdough seeded with all three starter cultures proved to be the most acceptable in terms of taste, texture, and overall acceptance. Some sourdough breads were not superior, in terms of their sensory quality, to $\mathrm{CO}$ bread and some were even classed as inferior. According to Crowley et al. (2002), the phenomenon of shrinkage which occurs in sourdough bread results in an increased firmness. During storage, staling occurred gradually and thus breads prepared from all treatments received lower scores. Sourdough breads can develop a pickled taste due to the production of organic acids by the LAB. Note that, there was no unanimity as to which of the treatments produced the best tasting bread, reflecting subjective differences between the panel members. Meignen et al. (2001) have documented that fermentation based on a combination of starter cultures produces a higher number of aromatic compounds than a single starter culture. In particular, fermentation with L. brevis was effective with respect to aromatic compounds, but a greater volume of acetic acid and other aromatic compounds was formed by the combined starter cultures.

\subsection{1 | Shelf life}

In sourdough-based breads, the appearance of mold was delayed compared with $\mathrm{CO}$ breads. The high moisture contents of these breads were responsible for their relatively short shelf life. The treatments producing the most mold-resistant breads were $1 \mathrm{C}, 2 \mathrm{C}$, 5C, 8C, 9C, 10C, 11C, 13C, 14C, and 15C.

\section{4 | CONCLUSION}

In conclusion, LAB with high EPS production, proteolytic activity, and acidification properties can be considered great for sourdough fermentation. Adding sourdough fermented with LAB reduced the hardness of the resulting bread, its elasticity, and the extent of baking loss. The optimal treatments were to use sourdough seeded with L. brevis (treatment 2C), with L. plantarum (treatment 4 C), with L. brevis + L. paralimentarius (treatment $8 C$ ), or with L. sanfranciscensis + L. brevis + L. paralimentarius (treatment 11C). The aforementioned strains, as suitable functional starter cultures for sourdough, could be used as starter cultures in gluten-free sourdough-based breads.

\section{ACKNOWLEDGMENTS}

The financial support of the Agricultural Biotechnology Research Institute of Iran (ABRII) [Grant number 3-05-0551-88020] is gratefully acknowledged. The authors declare no conflict of interests and no ethical issues were promulgated.

\section{DATA AVAILABILITY STATEMENT}

The data that support the findings of this study are available on request from the corresponding author. The data are not publicly available due to privacy or ethical restrictions.

\section{ORCID}

Mehran Aalami iD https://orcid.org/0000-0002-9946-0327

Mohammad Amin Hejazi iD https://orcid.

org/0000-0001-9739-9887

\section{ENDNOTES}

${ }^{1}$ Basic Local Alignment Search Tool.

${ }^{2}$ American Association of Clinical Chemistry.

\section{REFERENCES}

Aplevicz, K. S., Da Silva, T., Fritzen-Freire, C. B., Amboni, R. D., Barreto, P. L., \& Sant'Anna, E. S. (2014). Effect of the Incorporation of different freeze-dried cultures on the properties of sourdough bread. Journal of Culinary Science \& Technology, 12, 354-367. https://doi. org/10.1080/15428052.2014.904837

Axel, C., Röcker, B., Brosnan, B., Zannini, E., Furey, A., Coffey, A., \& Arendt, E. K. (2015). Application of Lactobacillus amylovorus DSM19280 in gluten-free sourdough bread to improve the microbial shelf life. Food Microbiology, 47, 36-44. https://doi.org/10.1016/j. fm.2014.10.005

Barber, B., Ortolá, C., Barber, S., \& Fernandez, F. (1992). Storage of packaged white bread. Zeitschrift Für Lebensmittel-Untersuchung Und Forschung, 194, 442-449. https://doi.org/10.1007/BF01197726

Clarke, C., Schober, T., \& Arendt, E. (2002). Effect of single strain and traditional mixed strain starter cultures on rheological properties of wheat dough and on bread quality. Cereal Chemistry, 79, 640-647. https://doi.org/10.1094/CCHEM.2002.79.5.640 
Corsetti, A., Gobbetti, M., De Marco, B., Balestrieri, F., Paoletti, F., Russi, L., \& Rossi, J. (2000). Combined effect of sourdough lactic acid bacteria and additives on bread firmness and staling. Journal of Agricultural and Food Chemistry, 48, 3044-3051. https://doi. org/10.1021/jf990853e

Crowley, P., Schober, T. J., Clarke, C. I., \& Arendt, E. K. (2002). The effect of storage time on textural and crumb grain characteristics of sourdough wheat bread. European Food Research and Technology, 214, 489-496. https://doi.org/10.1007/s00217-002-0500-7

Czerny, M., \& Schieberle, P. (2002). Important aroma compounds in freshly ground wholemeal and white wheat flour identification and quantitative changes during sourdough fermentation. Journal of Agricultural and Food Chemistry, 50, 6835-6840. https://doi. org/10.1021/jf020638p

Edema, M. O., \& Sanni, A. I. (2008). Functional properties of selected starter cultures for sour maize bread. Food Microbiology, 25, 616625. https://doi.org/10.1016/j.fm.2007.12.006

Esteller, M. S., Zancanaro, O., Palmeira, C. N. S., \& Da Silva Lannes, S. C. (2006). The effect of kefir addition on microstructure parameters and physical properties of porous white bread. European Food Research and Technology, 222, 26-31. https://doi.org/10.1007/ s00217-005-0103-1

Hüttner, E. K., Dal Bello, F., \& Arendt, E. K. (2010). Rheological properties and bread making performance of commercial wholegrain oat flours. Journal of Cereal Science, 52, 65-71. https://doi. org/10.1016/j.jcs.2010.03.004

Katina, K., Heiniö, R.-L., Autio, K., \& Poutanen, K. (2006). Optimization of sourdough process for improved sensory profile and texture of wheat bread. LWT-Food Science and Technology, 39, 1189-1202. https://doi.org/10.1016/j.lwt.2005.08.001

Kiani, A., Nami, Y., Hedayati, S., Jaymand, M., Samadian, H., \& Haghshenas, B. (2021). Tarkhineh as a new microencapsulation matrix improves the quality and sensory characteristics of probiotic Lactococcus lactis KUMS-T18 enriched potato chips. Scientific Reports, 11(1), 1-13. https://doi.org/10.1038/s41598-021-92095-1

Kumar, C. M., Sabikhi, L., Singh, A., Raju, P., Kumar, R., \& Sharma, R. (2019). Effect of incorporation of sodium caseinate, whey protein concentrate and transglutaminase on the properties of depigmented pearl millet based gluten free pasta. LWT, 103, 19-26. https://doi.org/10.1016/j.lwt.2018.12.071

Loponen, J., Mikola, M., Katina, K., Sontag-Strohm, T., \& Salovaara, H. (2004). Degradation of HMW glutenins during wheat sourdough fermentations. Cereal Chemistry, 81, 87-93. https://doi. org/10.1094/CCHEM.2004.81.1.87

Matos, M. E., \& Rosell, C. M. (2015). Understanding gluten-free dough for reaching breads with physical quality and nutritional balance. Journal of the Science of Food and Agriculture, 95, 653-661. https:// doi.org/10.1002/jsfa.6732

Meignen, B., Onno, B., Gélinas, P., Infantes, M., Guilois, S., \& Cahagnier, B. (2001). Optimization of sourdough fermentation with Lactobacillus brevis and baker's yeast. Food Microbiology, 18, 239-245. https:// doi.org/10.1006/fmic.2000.0395

Mert, I. D., Campanella, O. H., Sumnu, G., \& Sahin, S. "Gluten-Free Sourdough Bread Prepared with Chestnut and Rice Flour". In: 9th Baltic Conference on Food Science and Technology "Food for Consumer Well-Being"). 239.

Moore, M. M., Dal Bello, F., \& Arendt, E. K. (2008). Sourdough fermented by Lactobacillus plantarum FSTá1. 7 improves the quality and shelf life of gluten-free bread. European Food Research and Technology, 226, 1309-1316.

Moroni, A. V., Dal Bello, F., Zannini, E., \& Arendt, E. K. (2011). Impact of sourdough on buckwheat flour, batter and bread: Biochemical, rheological and textural insights. Journal of Cereal Science, 54, 195202. https://doi.org/10.1016/j.jcs.2011.04.008

Nami, Y., Gharekhani, M., Aalami, M., \& Hejazi, M. A. (2019). Lactobacillusfermented sourdoughs improve the quality of gluten-free bread made from pearl millet flour. Journal of Food Science and Technology, 56, 4057-4067.

Novotni, D., Čukelj, N., Smerdel, B., \& Ćurić, D. (2013). Quality attributes and firming kinetics of partially baked frozen wholewheat bread with sourdough. International Journal of Food Science \& Technology, 48, 2133-2142.

Poutanen, K., Flander, L., \& Katina, K. (2009). Sourdough and cereal fermentation in a nutritional perspective. Food Microbiology, 26, 693699. https://doi.org/10.1016/j.fm.2009.07.011

Rinaldi, M., Paciulli, M., Caligiani, A., Scazzina, F., \& Chiavaro, E. (2017). Sourdough fermentation and chestnut flour in gluten-free bread: A shelf-life evaluation. Food Chemistry, 224, 144-152. https://doi. org/10.1016/j.foodchem.2016.12.055

Ryan, L. A., Zannini, E., Dal Bello, F., Pawlowska, A., Koehler, P., \& Arendt, E. K. (2011). Lactobacillus amylovorus DSM 19280 as a novel foodgrade antifungal agent for bakery products. International Journal of Food Microbiology, 146, 276-283. https://doi.org/10.1016/j.ijfoo dmicro.2011.02.036

Sanz-Penella, J. M., Tamayo-Ramos, J. A., \& Haros, M. (2012). Application of bifidobacteria as starter culture in whole wheat sourdough breadmaking. Food and Bioprocess Technology, 5, 2370-2380. https://doi.org/10.1007/s11947-011-0547-1

Scarnato, L., Montanari, C., Serrazanetti, D. I., Aloisi, I., Balestra, F., Del Duca, S., \& Lanciotti, R. (2017). New bread formulation with improved rheological properties and longer shelf-life by the combined use of transglutaminase and sourdough. LWT-Food Science and Technology, 81, 101-110. https://doi.org/10.1016/j. Iwt.2017.03.042

Symons, L., \& Brennan, C. (2004). The influence of $(1 \rightarrow 3)(1 \rightarrow$ 4)- $\beta$-D-glucan-rich fractions from barley on the physicochemical properties and in vitro reducing sugar release of white wheat breads. Journal of Food Science, 69, C463-C467. https://doi. org/10.1111/j.1365-2621.2004.tb10989.x

Tamani, R., Goh, K., \& Brennan, C. (2013). Physico-chemical properties of sourdough bread production using selected Lactobacilli starter cultures. Journal of Food Quality, 36, 245-252.

Thiele, C., Gänzle, M. G., \& Vogel, R. F. (2002). Contribution of sourdough lactobacilli, yeast, and cereal enzymes to the generation of amino acids in dough relevant for bread flavor. Cereal Chemistry, 79, 45-51. https://doi.org/10.1094/CCHEM.2002.79.1.45

Vernocchi, P., Ndagijimana, M., Serrazanetti, D., Gianotti, A., Vallicelli, M., \& Guerzoni, M. E. (2008). Influence of starch addition and dough microstructure on fermentation aroma production by yeasts and lactobacilli. Food Chemistry, 108, 1217-1225. https://doi. org/10.1016/j.foodchem.2007.06.050

Wolter, A., Hager, A.-S., Zannini, E., Czerny, M., \& Arendt, E. K. (2014). Impact of sourdough fermented with Lactobacillus plantarum FST 1.7 on baking and sensory properties of gluten-free breads. European Food Research and Technology, 239, 1-12.

How to cite this article: Gharekhani, M., Nami, Y., Aalami, M., \& Hejazi, M. A. (2021). Sourdoughs fermented by autochthonous Lactobacillus strains improve the quality of gluten-free bread. Food Science \& Nutrition, 9, 6372-6381. https://doi.org/10.1002/fsn3.2609 